\title{
The role of second-neighbor effects in photoemission: Are silicon surfaces and interfaces special?
}

\author{
K. Z. Zhang, K. E. Litz, and M. M. Banaszak Holl ${ }^{\text {) }}$ \\ Chemistry Department, University of Michigan, Ann Arbor, Michigan 48109-1055 \\ F. R. McFeely \\ IBM T. J. Watson Laboratory, Yorktown Heights, New York 10598
}

(Received 22 August 1997; accepted for publication 4 November 1997)

\begin{abstract}
A widely used assignment scheme for Si $2 p$ core-level photoemission studies of silicon oxidation relies solely on the formal oxidation state of the silicon. The tacit assumption of this assignment methodology is that second-neighbor effects have no measurable effect on observed Si $2 p$ binding energies. In this letter, new experiments are combined with literature precedents to make the case that the second-neighbor effects play an important role in determining binding energy shifts. (C) 1998 American Institute of Physics. [S0003-6951(98)03101-5]
\end{abstract}

During the past few years, the proper interpretation of $\mathrm{Si}$ $2 p$ core level binding energy $(\mathrm{BE})$ shifts in $\mathrm{x}$-ray photoemission (XPS) spectra of $\mathrm{Si} / \mathrm{SiO}_{2}$ interfaces, an issue long regarded as both simple and settled, has become the subject of considerable and ongoing controversy. ${ }^{1}$ For a long time it was more or less universally held among the community of scientists studying silicon oxidation and the $\mathrm{Si} / \mathrm{SiO}_{2}$ interface that the core-level binding energy shifts had a simple and structurally unambiguous origin. The shifts (with respect to the bulk substrate $\mathrm{Si} 2 p$ ) of $0.9,1.7$, and $2.5 \mathrm{eV}$ $( \pm 0.1 \mathrm{eV})$ were held to arise from $\mathrm{Si}$ atoms bound to one, two, and three oxygen atoms, respectively. ${ }^{2-5}$ Use of this assignment scheme tacitly asserts that an enumeration of the first nearest neighbors constitutes a complete and sufficient specification of the emitting atom for spectroscopic assignment purposes. Thus the three interfacial silicon core-level peaks were each the unambiguous signature of silicon atoms in specific formal oxidation states $\mathrm{Si}^{+1}, \mathrm{Si}^{+2}$, and $\mathrm{Si}^{+3}$. This simple picture is not without intuitive appeal. The number of readily apparent oxygen-induced interface peaks in the XPS spectra is equal to the number of possible transitional formal oxidation states, and the rough incremental equality of the binding energy shifts is suggestive of a simple additive effect. $^{6}$ It was further surmised that if the formal oxidation state description were not functionally complete, and the effects of more distant oxygen atoms were not negligible, a presumed multiplicity of extended structures would give rise to a featureless continuum of binding energies in the $0-3 \mathrm{eV}$ range, not the observed three-peak structure. From an experimental standpoint, however, there was little, if any, direct experimental evidence which could be cited in support of the formal oxidation state (FOS) model. The systems to which it had been applied were universally amorphous ones, with distributions of structural moieties that were not independently known. The only benchmark system that provided any form of experimental test of the assignment scheme itself was water chemisborbed on $\mathrm{Si}(100)-2 \times 1$. In fact, the FOS assignment scheme is in good agreement with the peaks observed for the water derived model interface; however, the ability of this simple adsorbate system to test the FOS scheme was limited to one type of structural moiety. ${ }^{7,8}$

${ }^{a)}$ Electronic mail: mbanasza@umich.edu
Experiments designed to test the FOS assignment scheme in a system of reasonable complexity were provided by Banaszak Holl and McFeely, who exposed $\mathrm{H}_{8} \mathrm{Si}_{8} \mathrm{O}_{12}$ clusters to $\mathrm{Si}(100)-2 \times 1$ surfaces. These experiments suggested that second-neighbor effects were important for the interpretation of photoemission experiments at silicon/silicon oxide interfaces. ${ }^{9}$ These conclusions were bolstered by subsequent studies of the related clusters $\mathrm{H}_{12} \mathrm{Si}_{12} \mathrm{O}_{18}, \mathrm{H}_{14} \mathrm{Si}_{14} \mathrm{O}_{21}{ }^{10}$ $\mathrm{H}_{10} \mathrm{Si}_{10} \mathrm{O}_{15},{ }^{11}$ and on the chemically very different molecule silatrane. ${ }^{12}$ This assertion that second-neighbor effects are spectroscopically important has not gone unchallenged. Pasquarello et al. have performed theoretical calculations indicating that the effects of second-nearest neighbors on corelevel shifts are at most $0.15 \mathrm{eV} .{ }^{13}$ They also performed a calculation of the XPS spectrum of the $\mathrm{H}_{8} \mathrm{Si}_{8} \mathrm{O}_{12}$ cluster attached to $\mathrm{Si}(100)-2 \times 1$ and concluded that the peak attributed by Banaszak Holl and McFeely to the influence of the $\mathrm{O}_{3} \mathrm{Si}$ - moiety should be absent from the spectrum. ${ }^{14}$ If we desire any sort of detailed understanding of the structure of $\mathrm{Si} / \mathrm{SiO}_{2}$ interfaces, it is crucially important that we resolve the issue of the photoemission assignment methodology. Most models of the thermal interface have made explicit use of the formal oxidation state interpretation of the XPS results, reaching the conclusion that the interface must be compositionally graded over at least two layers; $;^{2,3,5,8}$ however, Banaszak Holl, Lee, and McFeely have shown that by including the possibility of strong second-nearest neighbor interactions, it is possible to reconcile the XPS results with models of the interface which are atomically abrupt on the silicon substrate side. ${ }^{15}$

To clarify the fundamental issues of this controversy, it is instructive to consider the domain of validity of the central proposition underlying the formal oxidation state model: a knowledge of nearest neighbors alone suffices to predict core-level BE shifts with spectroscopic accuracy. A cursory examination of a compilation of core-level BEs of gaseous free molecules shows that this proposition, in general, is indefensible. $^{16}$ There are clear cases in which a large number of electronegative atoms in the second coordination sphere can have a greater effect than a single direct electronegative substitution. Thus, if the formal oxidation state model for the interpretation of $\mathrm{Si} 2 p$ core-level spectra of $\mathrm{Si}$ surfaces is correct, this system must be regarded as some sort of special, simpler case. This could presumably arise from some sort of 
"special nature" of $2 p$ core-level spectroscopy, as opposed to XPS in general, or from specific features of the Si surface and interface electronic environment. Although the tabulation of gas phase $\mathrm{Si} 2 p$ binding energies is not extensive, it suffices to cast serious doubt on the notion that $\mathrm{Si} 2 p$ corelevel spectra constitute the requisite special case. ${ }^{16}$ Consider the molecules of the form $\left(\mathrm{CH}_{3}\right)_{3} \mathrm{Si}-\mathrm{X}(\mathrm{X}=\mathrm{H}, \mathrm{F}, \mathrm{Cl}$, and $\mathrm{OEt}$ ). Taking the trimethylsilane as a standard, the substitution of $\mathrm{F}$ and $\mathrm{Cl}$ yields $\mathrm{Si} 2 p$ binding energy shifts of 0.97 and $0.82 \mathrm{eV}$, respectively, values roughly in agreement with the shifts these elements induce in Si surface atoms. ${ }^{7}$ However, the ethoxy group induces a shift of only $0.11 \mathrm{eV}$, far less than the $0.9 \mathrm{eV}$ induced by the binding of an $\mathrm{OH}$ group to a silicon surface atom. In contrast, the binding energy difference between silane, $\mathrm{H}_{3} \mathrm{SiSiH}_{3}$, and siloxane, $\mathrm{H}_{3} \mathrm{SiOSiH}_{3}$, is $0.95 \mathrm{eV}$, close to the surface value for a single oxygen substituent. These examples illustrate, albeit for systems that are not exact analogs of the surface bound clusters, that the specification of nearest neighbors alone is insufficient for spectroscopically accurate prediction of $\mathrm{Si} 2 p$ corelevel binding energy shifts in free molecules. Thus, we are led inexorably to the conclusion that if the formal oxidation state model is true, the $\mathrm{Si}$ surfaces (and interfaces) themselves must be the source of the special simplifying conditions that cause core-level binding energies to depend only upon the chemical identity of the nearest neighbor atoms. Reasons why this may be the case have previously been advanced. Himpsel et al. took note of the high dielectric constant of $\mathrm{Si}^{7}{ }^{7}$ and discussed how this could simplify the spectroscopy. This possibility was discussed at length with regard to this particular controversy by Simpson et al. ${ }^{17}$

In this letter, we report the results of an experiment designed to test the possibility that dielectric screening at $\mathrm{Si}$ interfaces might serve to reduce the range over which neighboring atoms can influence binding energy shifts. The general procedure is to select a pair of molecules that show large differences in core-level binding energies in the gas phase due solely to variations in the second coordination sphere of the emitting atom. These molecules can then be physisorbed onto an appropriately prepared Si surface, and their binding energies remeasured. If the presence of the surface serves to mitigate the effects of the atoms in higher coordination spheres, one would expect the BE difference between the molecules to vanish, or at least decrease substantially. For this purpose we have chosen to examine the $\mathrm{P} 2 p \mathrm{BE}$ of the molecules trimethylphosphine, $\mathrm{P}\left(\mathrm{CH}_{3}\right)_{3}$, and its perfluorinated analog $\mathrm{P}\left(\mathrm{CF}_{3}\right)_{3} \cdot{ }^{18}$ Although identical through firstnearest neighbors, the $\mathrm{P} 2 p$ BEs differ by $2.8 \mathrm{eV}[136.25 \mathrm{eV}$ for $\mathrm{P}\left(\mathrm{CH}_{3}\right)_{3}$ and 139.05 for $\left.\mathrm{P}\left(\mathrm{CF}_{3}\right)_{3}\right]^{19}$ The use of a phosphorus core level has two advantages. First, phosphorus is a neighboring element in the periodic table to Si and has very similar core-level spectroscopic properties to $\mathrm{Si}$. For example, the atomic polarizabilities of $\mathrm{Si}$ and $\mathrm{P}$ are quite similar (5.38 and $3.63 \times 10^{-24} \mathrm{~cm}^{3}$, respectively, on an overall elemental scale of $0-50 \times 10^{-24}$ ), suggesting that initial state inductive effects on the $2 p$ core levels should be similar. ${ }^{20}$ In fact, the value of the atomic polarizability suggests that inductive effects should be somewhat larger for $\mathrm{Si}$, making tests with $\mathrm{P}$ effective lower bounds. Second, by avoiding a silicon containing system we avoid the confounding of the

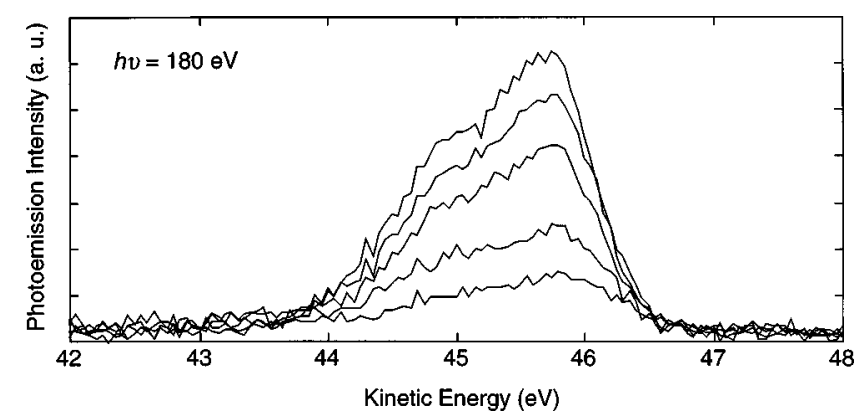

FIG. 1. P $2 p$ core-level spectra of $0.2-1.0$ monolayer coverages of $\mathrm{P}\left(\mathrm{CH}_{3}\right)_{3}$ on hydrogenated $\mathrm{Si}(111)$.

molecular signal with the substrate Si $2 p$, and make it extremely simple to demonstrate that no undesirable chemical reaction has taken place between the molecules and the surface.

Hydrogen terminated $\mathrm{Si}(111)$ surfaces were prepared by the method of Karlsson et al. in order to provide an inert silicon surface onto which the molecules could be physisorbed. ${ }^{21}$ Substrate cleanliness was verified by measuring XPS spectra in the $\mathrm{Si} 2 p, \mathrm{O} 1 s$, and $\mathrm{C} 1 s$ regions. Surfaces thus prepared were cooled to $-165^{\circ} \mathrm{C}$ and exposed to the molecules, after which the core-level spectra were obtained. Figure 1 shows the results of successive exposures of the above surfaces to trimethylphosphine. The P $2 p$ peak following each exposure consisted of a single spin-orbit split doublet peak, as would be expected from the low temperature physisorption of the intact molecules. Exposures in excess of $4.5 \mathrm{~L}$ produce no further spectral changes, indicating that the physisorption is self-limiting at 1 monolayer at this temperature, consistent with the attenuation of the $\mathrm{Si} 2 p$ core level. The P $2 p$ core-level binding energy for trimethylphosphine exhibits a small coverage dependence over the $0.2-1.0$ monolayer regime, with a total variation of $0.25 \mathrm{eV}$, a small quantity when compared to the $\mathrm{BE}$ range under investigation. As expected for physisorption, the $\mathrm{C} 1 s$ spectrum consisted of a single peak, and the Si $2 p$ spectrum gave no indication of strong interaction between the molecules and the substrate. Upon warming the substrate back to room temperature, the surface was essentially returned to its initial condition. No detectable P $2 p$ signal remained, and the surface contained only a trace of carbon. In summary, all of the experimental observations were consistent with the simple molecular physisorption expected.

The interaction of $\mathrm{P}\left(\mathrm{CF}_{3}\right)_{3}$ with the hydrogenated $\mathrm{Si}(111)$ surface was substantially weaker than that exhibited by trimethylphosphine. While the molecule could be successfully physisorbed at $-165{ }^{\circ} \mathrm{C}$ in the dosing chamber, it spontaneously desorbed from the surface in the spectrometer chamber on a time scale roughly equal to that necessary to obtain spectra of good statistical quality. Consequently, the spectra we report represent an average over a varying surface coverage. Although the $\mathrm{P} 2 p$ spectra of $\mathrm{P}\left(\mathrm{CF}_{3}\right)_{3}$ are well described by a single spin-orbit doublet peak, the linewidth is somewhat larger $(0.2 \mathrm{eV})$ than that of $\mathrm{P}\left(\mathrm{CH}_{3}\right)_{3}$. This could be arise from a small coverage dependence in the binding energy of $\mathrm{P}\left(\mathrm{CF}_{3}\right)_{3}$ analogous to that observed for $\mathrm{P}\left(\mathrm{CH}_{3}\right)_{3}$ over which our measurement averages, or from a greater degree of vibrational excitation in the final state of the fluorinated molecule, or from a combination of the two. 

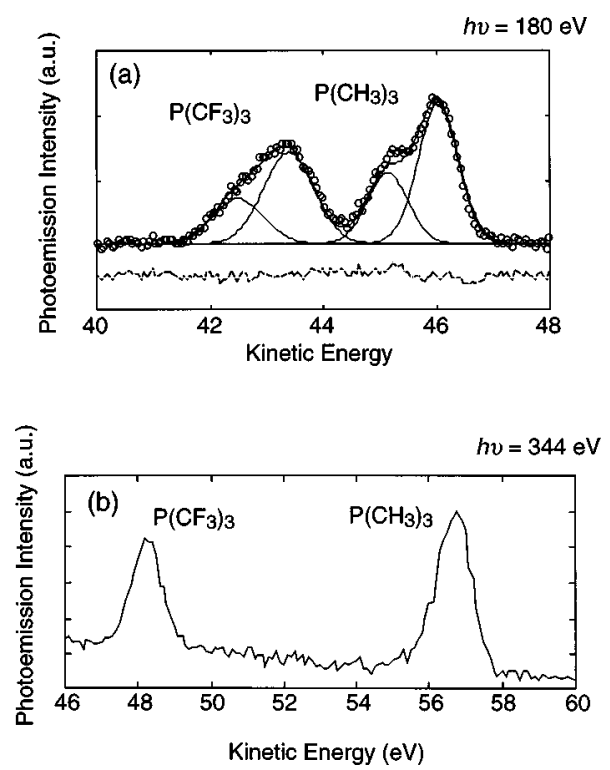

FIG. 2. (a) $\mathrm{P} 2 p$ core-level spectra of $\mathrm{P}\left(\mathrm{CF}_{3}\right)_{3}$ and $\mathrm{P}\left(\mathrm{CH}_{3}\right)_{3}$ coadsorbed on hydrogenated $\mathrm{Si}(111)$ at $-165^{\circ} \mathrm{C}$. Data are represented by open circles, fitted curves by solid lines, and the difference between the data and fit by a dashed line. (b) $\mathrm{C} 1 s$ core-level spectra of $\mathrm{P}\left(\mathrm{CF}_{3}\right)_{3}$ and $\mathrm{P}\left(\mathrm{CH}_{3}\right)_{3}$ coadsorbed on hydrogenated $\mathrm{Si}(111)$ at $-165^{\circ} \mathrm{C}$.

In order to make the most straightforward and direct comparison of the $\mathrm{P} 2 p$ binding energies of the two molecules a coadsorption experiment was performed. First the cooled, hydrogenated surface was exposed to $8 \mathrm{~L}$ of $\mathrm{P}\left(\mathrm{CF}_{3}\right)_{3}$. [The sticking coefficient of this molecule is substantially lower than for $\mathrm{P}\left(\mathrm{CH}_{3}\right)_{3}$.] Then the surface was exposed to $4.5 \mathrm{~L}$ of $\mathrm{P}\left(\mathrm{CH}_{3}\right)_{3}$, a saturation exposure. The $\mathrm{P} 2 p$ and $\mathrm{C} 1 s$ spectra produced by such coexposures are shown in Figs. 2(a) and 2(b), respectively. The P $2 p$ core-level spectrum shows two distinct doublet peaks corresponding to the two molecules. Scanning times were kept short in order to avoid excessive relative loss of the $\mathrm{P}\left(\mathrm{CF}_{3}\right)_{3}$ signal due to desorption. The peak separation of the two $\mathrm{P} 2 p_{3 / 2}$ peaks was determined by applying a standard least-squares peak fitting routine. The $\mathrm{P} 2 p_{3 / 2}$ binding energy difference between the two molecules was determined to be $2.6 \pm 0.1 \mathrm{eV}$, identical within experimental error to the reported gas phase separation of $2.8 \pm 0.1 \mathrm{eV} .{ }^{16,19}$ Thus, reduction of the secondneighbor derived BE shift by the silicon substrate is shown to be negligibly small. As a further check on the effect of the substrate on molecular BE differences, we measured $\mathrm{C} 1 \mathrm{~s}$ spectra of a coexposed surface [Fig. 2(b)]. As expected this spectrum consists of two widely separated lines. The measured splitting between the two $\mathrm{C} 1 s$ peaks is $8.5 \pm 0.1 \mathrm{eV}$ as compared to a value of $8.6 \pm 0.1 \mathrm{eV}$ reported for the gas phase. ${ }^{16,22}$ Given experimental uncertainties, this is essentially exact agreement.

The conclusion to be drawn from these experiments is straightforward. The presence of a silicon surface has been shown to have a negligible effect on the range over which electronegative atoms can influence the $2 p$ core level binding energy of a central phosphorus atom. Dielectric screening is not observed to reduce the effects of second neighbors upon the magnitude of core-level BE shifts. Silicon, lying immediately to the left of $\mathrm{P}$ in the periodic table, should show essentially the same behavior. If anything, secondneighbor effects for Si $2 p$ core levels should be somewhat greater because $\mathrm{Si}$ is the larger, more polarizable element of the two. Therefore, any system of assignment of Si $2 p$ binding energies which arbitrarily neglects the effects of atoms beyond the first coordination sphere has the potential of making serious errors, exactly as would be the case were such a scheme applied to free molecules. Viewed from this perspective, the conclusion that $\mathrm{O}_{3} \mathrm{Si}$-moieties can induce significant chemical shifts in the $2 p$ core level binding energy of a surface silicon atom, far from being a revolutionary assertion, is a profoundly conservative one.

Portions of this work were carried out at the National Synchrotron Light Source, Brookhaven National Laboratory, which is supported by the Department of Energy (Division of Materials Science and Division of Chemical Sciences). M.M.B.H. thanks the NSF (DMR-9596208) and IBM for financial support of this work.

${ }^{1}$ F. R. McFeely, K. Z. Zhang, M. M. Banaszak Holl, S. Lee, and J. E. Bender, J. Vac. Sci. Technol. B 14, 2824 (1996).

${ }^{2}$ For a general introduction to the area, see, for example, The Physics and Chemistry of $\mathrm{SiO}_{2}$ and the $\mathrm{Si}-\mathrm{SiO}_{2}$ Interface 2, edited by H. Z. Massoud, E. H. Poindexter, and C. R. Helms (The Electrochemical Society, Pennington, NJ, 1996).

${ }^{3}$ F. J. Grunthaner and P. J. Grunthaner, Mater. Sci. Rep. 1, 65 (1986).

${ }^{4}$ G. Hollinger, Appl. Surf. Sci. 8, 318 (1981).

${ }^{5}$ F. J. Himpsel, F. R. McFeely, A. Taleb-Ibrahimi, J. A. Yarmoff, and G. Hollinger, Phys. Rev. B 38, 6084 (1988).

${ }^{6}$ The principle of additivity of shifts is grounded is some of the earliest work on photoemission, see, for example U. Gelius, P.-F. Hedén, J. Hedman, B. J. Lindberg, R. Manne, R. Nordberg, C. Nordling, and K. Siegbahn, Phys. Scr. 2, 70 (1970); J. Hedman, M. Klasson, B. J. Lindberg, and C. Nordberg, in Electron Spectroscopy, edited by D. A. Shirley (NorthHolland, Amsterdam, 1972), p. 681.

${ }^{7}$ F. J. Himpsel, F. R. McFeely, J. F. Morar, A. Taleb-Ibrahimi, and J. A. Yarmoff, Proceedings of the 1988 Enrico Fermi School on Photoemission and Absorption Spectroscopy of Solids and Interfaces with Synchrotron Radiation (North-Holland, Varenna, 1988).

${ }^{8} \mathrm{~A}$ variety of structures has been proposed for silicon/silicon oxide interfaces. See, for example, Refs. 3 and 5; also T. Engel, Surf. Sci. Rep. 18, 91 (1993); T. Hattori, Crit. Rev. Solid State Sci. 20, 339 (1995), and references therein.

${ }^{9}$ M. M. Banaszak Holl and F. R. McFeely, Phys. Rev. Lett. 71, 2441 (1993).

${ }^{10}$ S. Lee, S. Makan, M. M. Banaszak Holl, and F. R. McFeely, J. Am. Chem. Soc. 116, 11819 (1994)

${ }^{11}$ K. Z. Zang, L. M. Meeuwenberg, M. M. Banaszak Holl, and F. R. McFeely, Jpn. J. Appl. Phys., Part 1 36, 1622 (1997).

${ }^{12}$ K. Z. Zhang, M. M. Banaszak Holl, J. E. Bender, S. Lee, and F. R. McFeely, Phys. Rev. B 54, 7686 (1996).

${ }^{13}$ A. Pasquarello, M. S. Hybertson, and R. Car, Phys. Rev. B 53, 10942 (1996).

${ }^{14}$ A. Pasquarello, M. S. Hybertson, and R. Car, Phys. Rev. B 54, R2339 (1996).

${ }^{15}$ M. M. Banaszak Holl, S. Lee, and F. R. McFeely, Appl. Phys. Lett. 65, 1097 (1994).

${ }^{16}$ W. L. Jolly, K. D. Bomben, and C. J. Eyermann, At. Data Nucl. Data Tables 31, 433 (1984).

${ }^{17}$ W. C. Simpson, J. A. Yarmoff, W. H. Hung, and F. R. McFeely, Surf. Sci. 355, L283 (1996).

${ }^{18} \mathrm{P}\left(\mathrm{CH}_{3}\right)_{3}$ was purchased from Aldrich Chemical Co. and redistilled four times; $\mathrm{P}\left(\mathrm{CF}_{3}\right)_{3}$ was synthesized via the literature procedure; F. W. Bennet, H. J. Emeléus, and R. N. Haszeldine, J. Chem. Soc. 1565 (1953).

${ }^{19}$ R. N. Sodhi and R. G. Cavell, J. Electron Spectrosc. Relat. Phenom. 32, 283 (1983).

${ }^{20}$ T. M. Miller and B. Bederson, Adv. At. Mol. Phys. 13, 1 (1977).

${ }^{21}$ C. J. Karlsson, E. Landemark, L. S. O. Johansson, U. O. Karlsson, and R. I. G. Uhrberg, Phys. Rev. B 41, 1521 (1990).

${ }^{22}$ T. H. Lee, W. L. Jolly, A. A. Bakke, R. Weiss, and J. G. Verkade, J. Am. Chem. Soc. 102, 2631 (1980); W. B. Perry, T. F. Schaaf, and W. L. Jolly, ibid. 97, 4899 (1975). 